\title{
THROMBOTIC THROMBOCYTOPENIC PURPURA
}

\author{
REPORT OF A CASE PRESENTING AS A CHRONIC \\ NEUROLOGICAL DISORDER AND CHARACTERIZED \\ BY UNUSUAL HISTOLOGICAL FINDINGS
}

\author{
BY \\ B. BORNSTEIN, J. H. BOSS, J. CASPER, AND M. BEHAR \\ From the Departments of Neurology and Pathology, Beilinson Hospital, Petah-Tiqua, Israel
}

(RECEIVED FOR PUBLICATION OCTOBER 20, 1959)

\begin{abstract}
A case of thrombotic thrombocytopenic purpura in a 50-year-old woman is described. Almost the whole course of the disease, lasting 18 months, was characterized by a bizarre neurological disorder, and the haematological manifestations first appeared at a late stage.

In many organs a vast number of arterioles and capillaries contained plugs of a fibrinoid material, and fibrinoid was subendothelially accumulated in a few of these vessels ; but, in addition, mediumsized arteries of the myocardium were also obstructed by this same material. There were also verrucal endocardiosis of the mitral valve and slight thickening of the glomerular basement membranes. The striking diffusion of a pathological substance through damaged cerebral vessel walls into the nervous tissue seems to be a significant contribution to the understanding of the pathogenesis of the vascular pathology of thrombotic thrombocytopenic purpura.
\end{abstract}

Thrombotic thrombocytopenic purpura is still a rare disease (Frick and Hitzig, 1959), and the publication of another single case merits attention if new knowledge emerges. We report herewith a case distinguished by a chronic, remittent course lasting 18 months. The histological findings, though altogether typical, presented some peculiarities worthy of note.

The numerous synonyms given to this syndrome indicate some of the prevailing differences of opinion concerning the nature of the underlying pathological process, e.g., platelet thrombosis syndrome (Beigelman, 1951; Symmers and Barrowcliff, 1951), thrombotic microangiopathy (Symmers, 1956), thrombocytopenic purpura with vasothrombosis (Engel, Scheinker, and Humphrey, 1947), disseminated thrombocytic thrombosis (Wyatt and Lee, 1950), thrombotic acroangiothrombosis (Adams, Cammermeyer, and Fitzgerald, 1948). Craig and Gitlin (1957) speak of "hyaline thrombi" in thrombotic thrombocytopenic purpura, and Stuart and MacGregorRobertson (1956) refer to it as a "hyperergic microangiopathy." The salient clinical and pathological features are amply recorded in the literature (Adams et al., 1948 ; Gore, 1950 ; Hauser, Beyer, and Burger, 1951; Ladwig, 1953 ; Meacham, Orbison, Heinle, Steele, and Schaefer, 1951; O’Brien and Sibley, 1958). All the cases reported till 1959 had a fatal outcome. The early use of steroids and A.C.T.H. may be beneficial (Burke and Hartmann, 1959). The main clinical manifestations are fever, haemolytic anaemia, thrombocytopenia, purpura, and involvement of various organs with the relative exclusion of the lungs; the central nervous system and the kidneys are most often involved, but the myocardium (Frick and Hitzig, 1959), gastrointestinal tract (Hellstrom, Nash, and Fisher, 1959), spleen (Gore, 1950), lymph nodes (Beigelman, 1951), and other organs are occasionally also clinically involved. The involvement of the central nervous system, which can appear at an early or late phase, is an almost constant feature. The complicated clinical picture is the sequel of widely disseminated arterioles and capillaries containing "thrombotic" lesions. which are associated with degenerative damage of $\mathrm{w}$ the vessel walls and aneurysmal dilatation, particularly at the arteriolar-capillary junction (Orbison, 1952). The nature of the occlusive material is not yet established with certainty.

\section{Case Report}

H. H., a 50-year-old housewife, mother of a healthy $\frac{?}{\Phi}$ girl of 14, suffered since her youth from attacks of $\stackrel{\unrhd}{\varrho}$ headache accompanied by nausea and vomiting, occurring several times a year. Her present illness 
began suddenly; while at work, she experienced a sudden, severe headache, vomited, and felt weakness of the left upper limb. For about 10 minutes her speech was unintelligible. A few hours later she noticed weakness of the left lower limb too. The patient was admitted to another hospital, where left hemiplegia was diagnosed. Her condition improved rapidly, but movements of the left hand and fingers remained somewhat impaired. Her speech was unaffected. The blood pressure was $140 / 95 \mathrm{~mm}$. $\mathrm{Hg}$. The blood picture and urine were normal.

Four months later, a sudden speech disturbance occurred, which, according to the description of the patient's relatives, was interpreted as a motor-sensory aphasia. After a few days only slight verbal aphasia remained, but the patient's mental demeanour changed ; she became irritable, weepy, and forgetful. Shortly thereafter she once more experienced an attack of headache accompanied by vomiting and speech disturbance. The patient was referred to the neurological department of the Beilinson Hospital.

Examination revealed a pale undernourished woman not in acute distress. She spoke remarkably slowly and had great difficulty in finding the right words, but she was well orientated and gave a clear anamnesis. Her body temperature was $100^{\circ} \mathrm{F}$., blood pressure $140 / 90 \mathrm{~mm}$. $\mathrm{Hg}$, pulse rate 96 per minute. No abnormalities of the thoracic and abdominal organs were found. A left hemiparesis, more pronounced in the upper limb and especially involving the distal parts, was noted. The muscles were hypertonic and the reflexes were hyperactive bilaterally, but more so on the left side. The left abdominal reflexes were absent. Babinski's, Oppenheim's and Chaddeck's signs were present on the left side. The right plantar reflex was not elicitable and Babinski's sign was found at times. Sensation was intact. The pupils and eye grounds were normal. $X$-ray examination of the skull showed no abnormality. Laboratory findings were as follows: sedimentation rate $18 \mathrm{~mm}$. per hour (Westergren), haemoglobin 8.6 g. per $100 \mathrm{ml}$., red blood cells 2,900,000, white blood cells 6,200 ; the platelets were not counted, but mentioned as being normal; blood sugar was $96 \mathrm{mg}$. per $100 \mathrm{ml}$., urea $30 \mathrm{mg}$. per $100 \mathrm{ml}$. Analysis of urine was negative. The cerebrospinal fluid was clear, its pressure normal, the Pandy test negative, protein $36 \mathrm{mg}$. per $100 \mathrm{ml}$., sugar $88 \mathrm{mg}$. per $100 \mathrm{ml}$. On the electroencephalographic tracings slow waves (3-6 per minute) of low voltage were recorded in the anterior and middle regions of the left temporal lobe. The family declined ventriculography. During the following days the patient's condition improved considerably. Because of the anaemia iron therapy was instituted. The patient was discharged in a satisfactory state; the haemoglobin was $11.3 \mathrm{~g}$. per $100 \mathrm{ml}$., red blood cells $3,450,000$ and platelets 180,000 .

At home the patient's condition deteriorated gradually and necessitated admission to hospital for the third time, 10 months after her last discharge. According to the history given by the family, she went through repeated episodes characterized by headache and vomiting, disturbances of speech and memory. Several times convulsive movements of the left body side, and later also of the right side, were observed. From time to time the patient was febrile. On the day before admission, a sudden right paralysis and complete loss of speech occurred.

Examination disclosed a right hemiplegia, hypertonic muscles, and pathological reflexes. A complete motor-sensory aphasia was noted. Testing of sensation was uncertain. The Rumpel-Leede phenomenon was positive. The blood pressure was $140 / 90 \mathrm{~mm}$. Hg. The eye grounds were normal. Lumbar puncture revealed clear fluid under raised pressure and containing 6 cells per c.mm., the Pandy test was negative, protein $49 \mathrm{mg}$. per $100 \mathrm{ml}$. Laboratory findings were as follows: sedimentation rate $19 \mathrm{~mm}$. per hour (Westergren), Wassermann reaction negative, urea $48 \mathrm{mg}$. per $100 \mathrm{ml}$., haemoglobin $9.7 \mathrm{~g}$. per $100 \mathrm{ml}$., red blood cells $3,800,000$, white blood cells 11,650 with a normal differential, platelets 37,000 . The bleeding time was three and a half minutes and coagulation time seven minutes. A red blood cell fragility test gave the following results: haemolysis began at a concentration of $0.48 \% \mathrm{NaCl}$ and the process was complete at a concentration of $0.25 \%$ $\mathrm{NaCl}$. Urine analysis disclosed up to 30 fresh red blood cells per high-power field and many granulated casts in the deposit. In the days following, the patient's course went rapidly downhill, many cutaneous petechial and ecchymatous haemorrhages appeared all over the body, and blood examination revealed progressive anaemia (haemoglobin $7.6 \mathrm{~g}$. per $100 \mathrm{ml}$, red blood cells 2,700,000, haematocrit $23 \%$ (reticulocytes $16 \%$ per c.mm., platelets 30,000). The patient lapsed into coma and expired 48 hours later.

\section{Necropsy Findings}

The body was that of a thin, middle-agedlooking woman. There was no jaundice. Many cutaneous and deep subcutaneous petechial and ecchymatous haemorrhages were scattered all over the body.

The left pleural cavity contained a serous effusion of $200 \mathrm{ml}$. The lungs were emphysematous, congested, and oedematous. There were moderate tracheobronchitis and bronchopneumonic foci in both lower lobes. The heart was of normal size $(340$ g.) and configuration. Subendocardial petechial haemorrhages were found in the left ventricle. The myocardium of both ventricles was marked by numerous tiny haemorrhages. The anterior wall of the left ventricle contained numerous scars, 1 to $2 \mathrm{~mm}$. in diameter. On the dorsal cusp of the otherwise normal-appearing mitral valve a small group of tiny, soft, and reddish vegetations was situated. The coronary arteries were within normal limits, as were all the great body arteries. The alimentary 

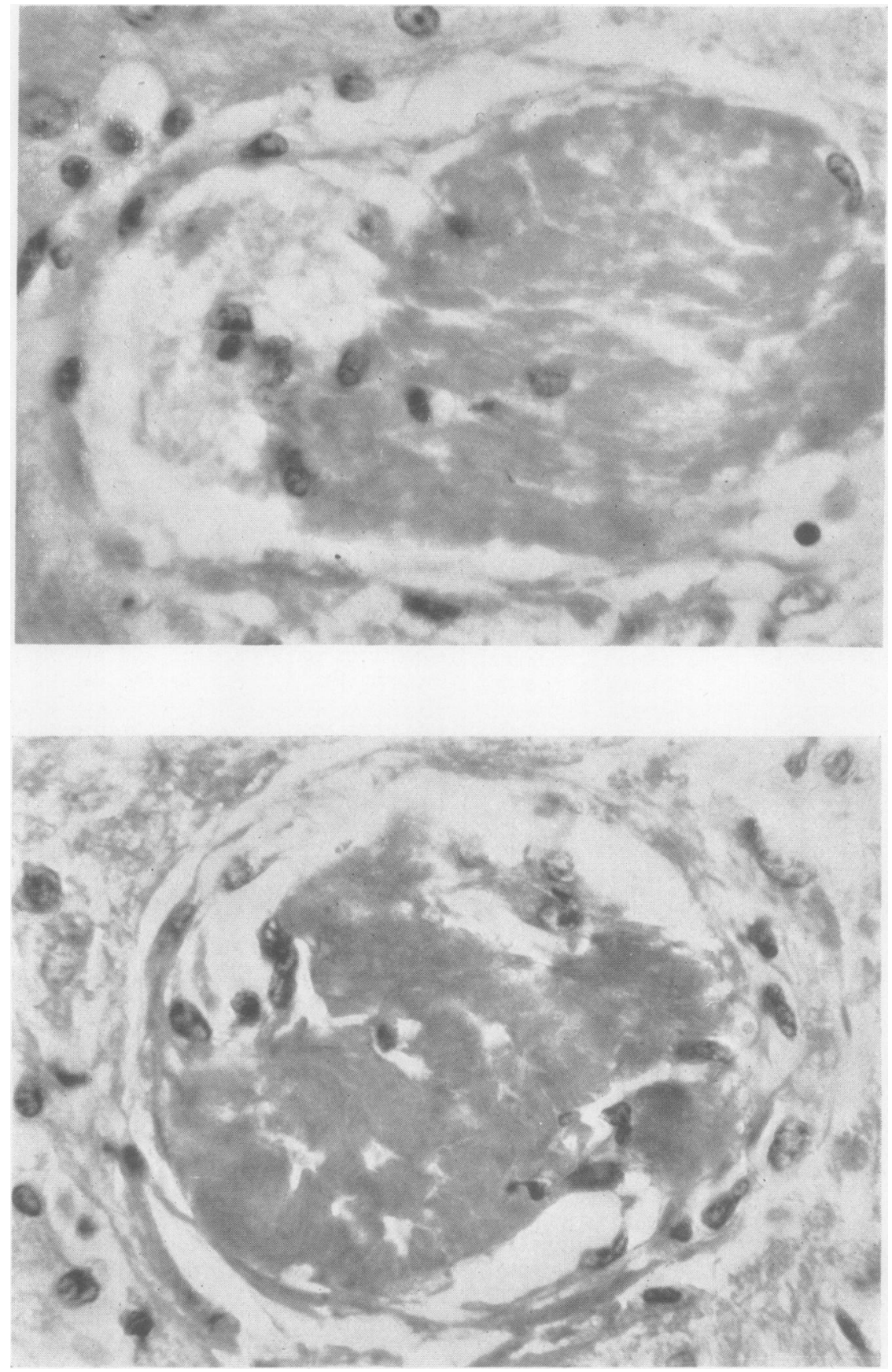

FIG. 1.-The typical lesion of thrombotic thrombocytopenic purpura. Dilated cerebral arterioles containing plugs of a smudgy and granular, eosinophilic material, within which a few cells are enmeshed. Haematoxylin and eosin. $\times 360$. 
tract was intact. The liver weighed $1,530 \mathrm{~g}$. , and its lobular pattern was accentuated due to a moderate degree of centrilobular congestion. The spleen was small (80 g.), its parenchyma normal. The pancreas contained small haemorrhages, which were scattered here and there in groups. The kidneys were rather small (combined weight 230 g.), the capsules stripped with ease, the surfaces were irregular, the cortices were pale, the cortico-medullary junction was distinct. Many petechial haemorrhages were scattered throughout the cortices. The pelvices, ureters and urinary bladder were normal. The adrenal glands showed nothing of note. The internal genital organs were atrophic.

The brain was anaemic and oedematous. The walls of the larger arteries were delicate and the lumina were patent. Coronal sections disclosed numerous old and recent, variously sized and shaped encephalomalacic foci in both cerebral hemispheres. The majority were located in the cortical and subcortical areas, but some were also found elsewhere, namely, in the white matter of the left frontal, right temporal and left occipital lobes, and on the right side in the internal capsule, putamen, caudate nucleus, corona radiata, and surrounding the posterior cornu of the lateral ventricle. No lesions were present in the cerebellum, pons, and medulla oblongata.

\section{Microscopic Examination}

The outstanding histological finding was partial or complete occlusion of an excessive number of arterioles and capillaries by plugs consisting of a smudgy, granular, eosinophilic, periodic-acidSchiff-positive and argyrophilic (Gomori's method) material, in which no fibrin could be demonstrated (henceforth to be referred to as "thrombotic" material). There was no inflammatory infiltrate associated with these lesions. Fig. 1 illustrates, for example, a typical lesion in the brain. The material either lay in the lumen unattached to the vessel wall in the plane of section or it was attached to the wall; sometimes it was covered by a layer of endothelial cells and/or contained endothelial cells or fibroblasts within it, and rarely it was replaced by a loose connective tissue. Some of the vessels were markedly dilated. In relatively few vessels there was a subendothelial accumulation of hyaline, eosinophilic, periodic-acid-Schiff-positive material, at times blurring the structure of the wall. This was either localized to a part of the circumference or encircled it completely. The subendothelial deposit was either in continuity with an intraluminal plug or it occurred independently.

Kidneys.-Many glomeruli were intact, but others showed a slight thickening of the basement membranes of the capillary walls and of the basement membranes of the Bowman's capsules. Many of the vasa afferentia, but only relatively few glomerular capillaries, vasa efferentia and arterioles and capillaries of the interstitial tissue contained "thrombotic" material. Fig. 2 demonstrates such a finding, involving the afferent and efferent arterioles as well as some capillaries of one glomerulus. Many proximal tubules were dilated and their epithelial cells contained accumulations of hyaline droplets. Hyaline casts, which gave a positive Prussian blue reaction, were present in the tubules.

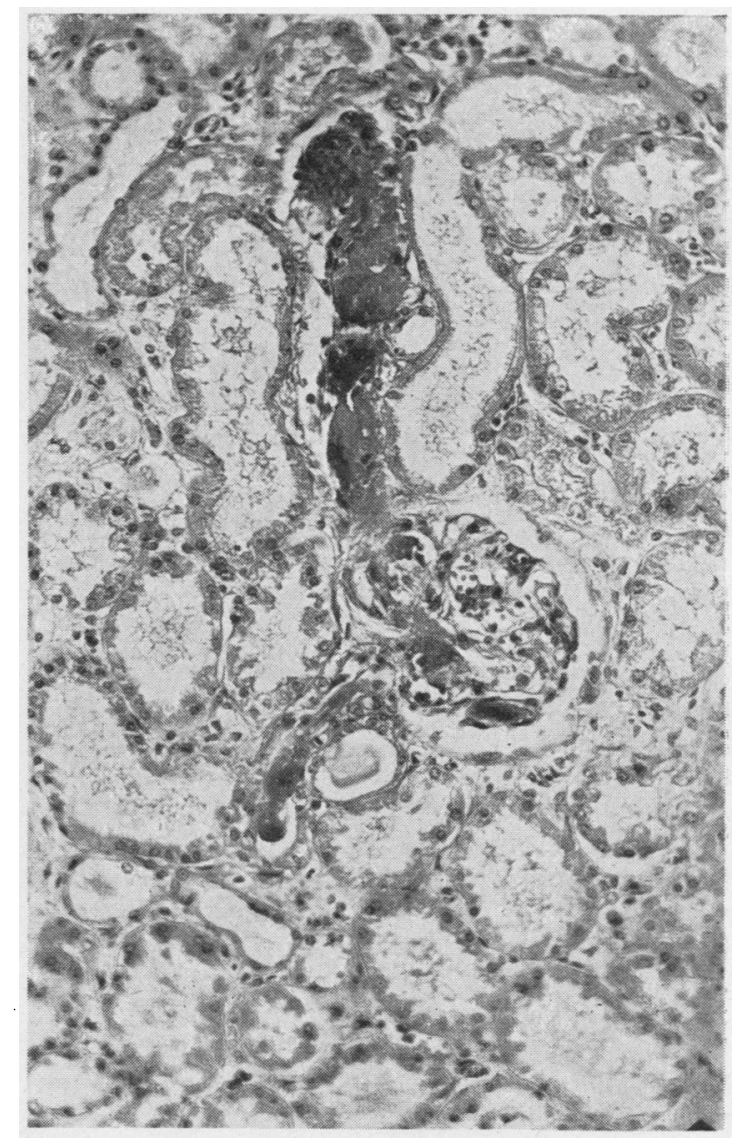

Fig. 2.-Plugging of the afferent and efferent arterioles in the kidney as well as some glomerular capillaries. Dilated proximal convoluted tubules. Haematoxylin and eosin. $\times 190$. 


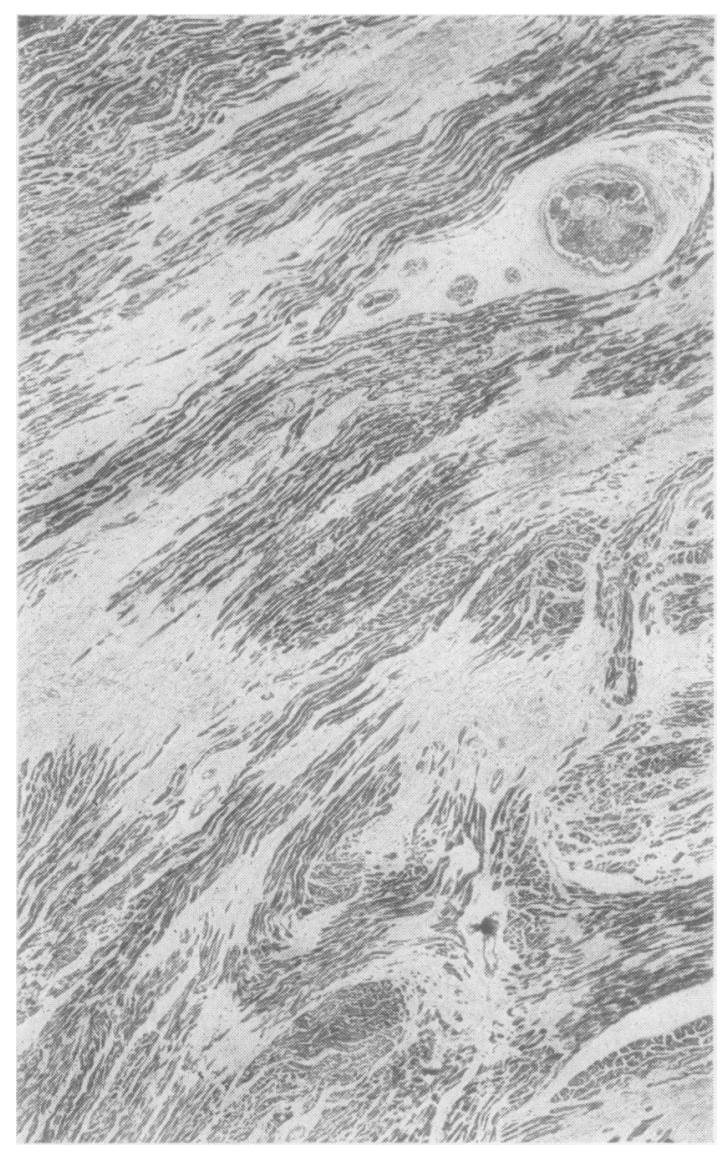

FIG. 3.-Patchy fibrosis of the myocardium. A medium-sized artery and some arterioles contain "thrombotic" lesions. Haematoxylin and eosin. $\times 40$

Heart.-Fig. 3 shows a representative section of the ventricular myocardium. The continuity of the muscle fibres was disrupted by areas of scar and granulation tissue of various sizes and shapes. Many muscle fibres were hypertrophic. In the septal myocardium foci of recent infarction were seen. Numerous arterioles and capillaries contained "thrombotic" material and a few were occluded by fibroblastic proliferation. In contradistinction to the other organs, also medium-sized arteries were involved in the process (Figs. 3 and 4); their lumina were partially or completely obstructed by connective tissue and/or the "thrombotic" mass. Fig. 4 illustrates a medium-sized artery, the lumen of which was narrowed by a signetring-shaped fibrous thickening of the intima, endothelialized except on its summit, to which was adherent a polypous structure composed of a smudgy, eosinophilic, argyrophilic and periodic-
acid-Schiff-positive material devoid of fibrin (as demonstrated by the Weigert's and phosphotungstic-acid-haematoxylin stains); it contained a few fibroblasts and was partly endothelialized.

The vegetations on the dorsal cusp of the mitral valve, which was focally hyalinized, consisted of material morphologically and tinctorially indistinguishable from that contained in the blood vessels.

Lungs-There were intra-alveolar haemorrhages and large accumulations of alveolar phagocytes containing haemosiderin. "Megakaryocyte embolization," as demonstrated in the capillaries of the interalveolar septa by the P.A.S. stain (Sharnoff and Kim, 1958), was extensive. No vessels containing "thrombotic" material were found.

Pancreas.-Many small foci of acute pancreatic necrosis, associated with arterioles and capillaries containing "thrombotic" lesions, and recent interstitial haemorrhages were scattered throughout the organ. The capillaries of the Langerhans' islets were heavily involved and here and there an intrainsular haemorrhage was noted.

Liver.-Acute passive congestion, a few "thrombotic" lesions, and haemosiderosis were observed.

Spleen.-There were acute passive congestion, swelling of the littoral cells, a few "thrombotic" lesions, periarteriolar fibrosis and haemosiderosis.

Lymph Nodes.-The lymphatic component was decreased in amount and there were no germinal centres ; a few "thrombotic" lesions and a remarkable degree of haemosiderosis existed.

Adrenal Glands. - In the zona glomerulosa there were numerous "thrombotic" lesions; the zona fasciculata, on the other hand, was the site of small interstitial haemorrhages.

Oesophagus, Thyroid Gland, and Skeletal Muscle.-Only very few blood vessels contained "thrombotic" lesions.

Skin.-No "thrombotic" lesions could be demonstrated, though the cutaneous and subcutaneous tissues were sprinkled by extravasated blood cells.

Bone Marrow.-The erythropoiesis was active ; the megakaryocytes were increased in number. A few macrophages contained haemosiderin. There were no vessels containing "thrombotic" material.

Brain.-The brain was markedly oedematous ; in different areas there were lesions ranging from most recent ischaemic infarction and diffuse 
or perivascular haemorrhages to older foci of malacia characterized by the appearance of scavenger cells and reactive gliosis. In the oedematous regions and in the meninges there were only a few blood vessels containing "thrombotic" material. On the other hand, in the severely damaged tissue, as well as in the choroid plexus, the "thrombotic" lesions were numerous. It should be emphasized that in the older foci of malacia only few vessels were obstructed by fibroblastic proliferation, whereas most of the involved arterioles and capillaries contained unaltered "thrombotic" material. In multiple sections from oedematous regions, diffusion of a periodic-acid-Schiff-positive material through the vessel walls was found (Fig. 5). Small blood vessels, the walls of which were slightly thickened due to inhibition by periodic-acidSchiff-positive material, were surrounded by

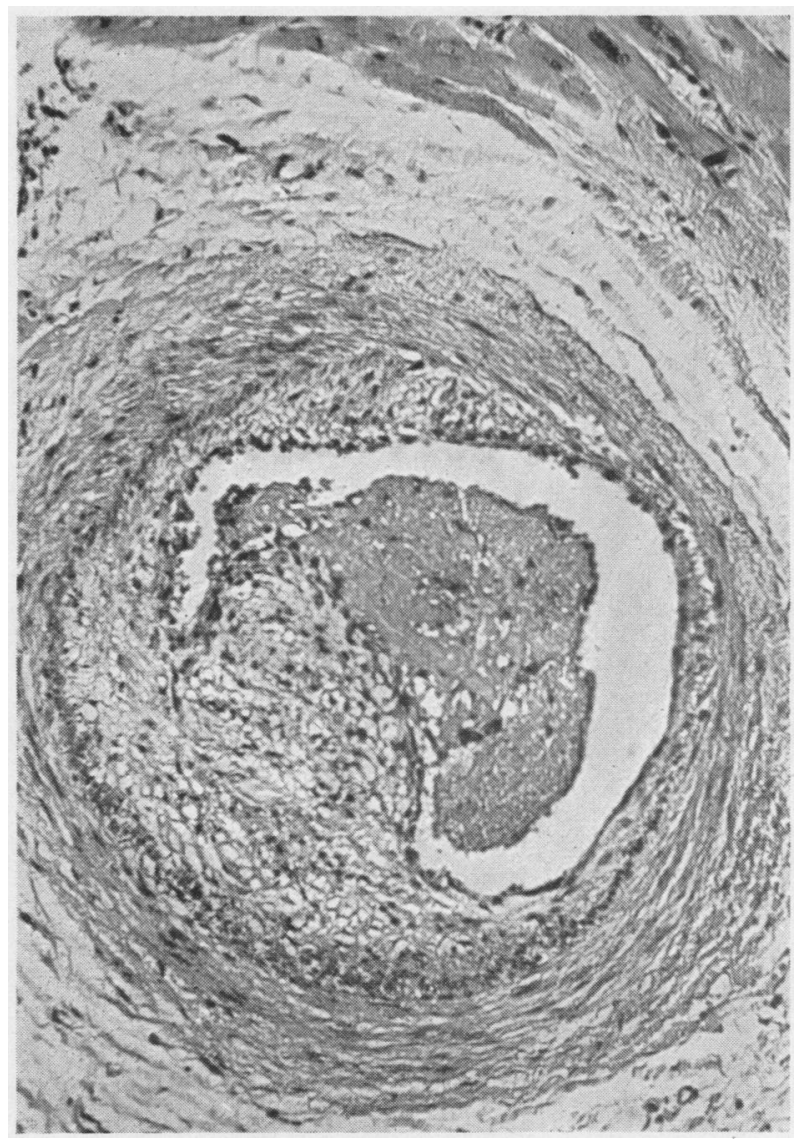

FIG. 4.-Narrowing of the lumen of a medium-sized artery in the heart by a signet-ring-shaped fibrous intimal thickening, to which is attached a "thrombotic" polypous structure. Haematoxylin and eosin. $\times 100$. confluent, roundish to polygonal masses of a periodic-acid-Schiff-positive substance infiltrating deep into the adjacent nervous tissue. This unusual picture reminded one to a certain extent of the so-called "grape-like bodies" of Buscaino (Jakob, 1927). Corresponding sections, stained with phosphotungstic-acid-haematoxylin, revealed an almost complete absence of the neuroglia in those places where the periodic-acid-Schiff-positive material was deposited (Fig. 6).

In the hypophysis, the blood vessels of the anterior lobe appeared normal, whereas many arterioles and capillaries of the posterior lobe contained " thrombotic" lesions.

\section{Comment and Further Investigation}

Several features of the presented case are apparently atypical and unusual. The patient's illness, masquerading as a neurological disorder, lasted 18 months and the haematological manifestations appeared only terminally. Histological evidence of involvement of medium-sized arteries in the heart and verrucal endocardiosis (Allen and Sirota, 1944) were found. Middle-sized arteries containing "thrombotic" lesions were also observed by Cooper, Stickney, Pease, and Bennett (1952), and vegetations on the cusps of the aortic valve were present in one of Beigelman's (1951) cases and on the cusps of the mitral valve in the case reported by Engel et al. (1947). In the brain there was diffusion of a periodic-acid-Schiff-positive material through damaged vessel walls into the nervous tissue. The diagnosis of thrombotic thrombocytopenic purpura in this case is based on the clinical picture of an intermittent bizarre neurological disorder associated with fever, anaemia, thrombocytopenia, and purpura ; the microscopic picture was characterized by the presence of widely disseminated arterioles and capillaries containing a smudgy, granular, eosinophilic material and a degenerative alteration of the vessel walls, i.e., subendothelial accumulation of hyaline eosinophilic material.

Accepting the case as an authentic example of thrombotic thrombocytopenic purpura, it seems to us that verrucal endocardiosis and involvement of medium-sized arteries can be part of the syndrome. The question arises whether the material found in these arteries is identical to or different from that present in the arterioles and capillaries. Because the exact composition of the "thrombotic" 


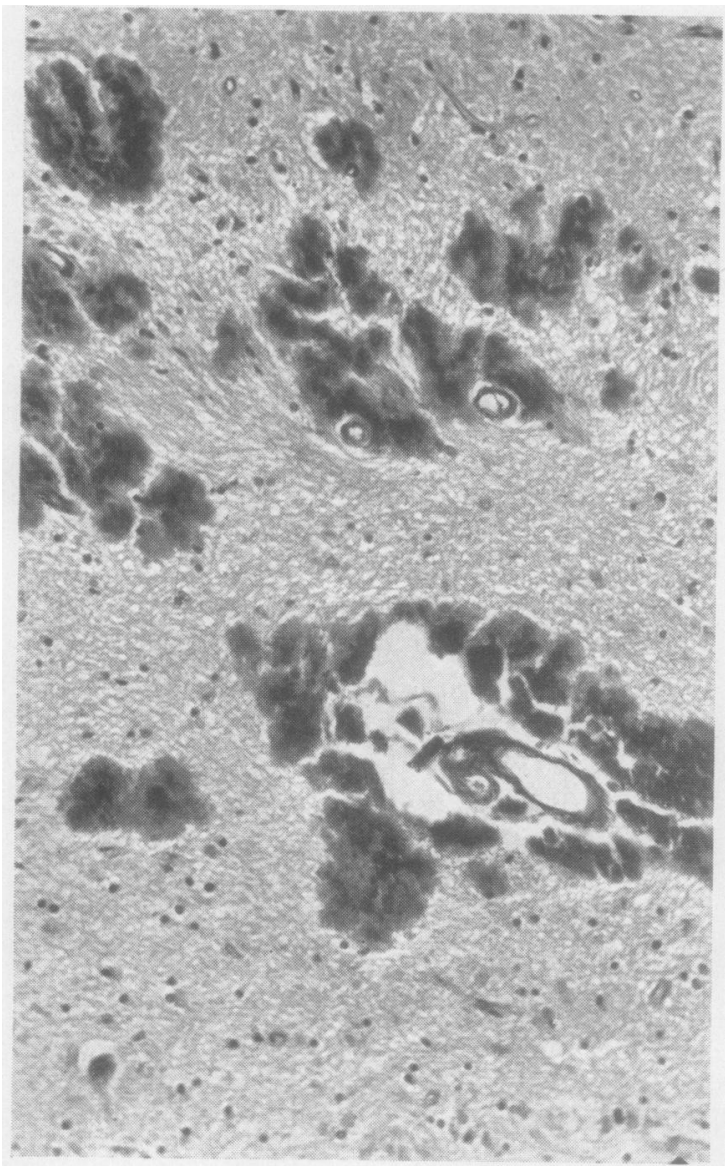

FIG. 5.-In the brain, surrounding slightly thickened arterioles and capillaries, there are confluent, roundish to polyhedral, periodicacid-Schiff-positive masses. Periodic-acid-Schiff. $\times 80$.

material can be defined neither morphologically nor on staining, we subjected the lesion of medium-sized arteries to digestion with trypsin.

Serial sections of the area illustrated in Fig. 4 were cut and alternating sections were submitted to tryptic digestion. The other sections were used as controls. After deparaffination and hydration, the slides were immersed in a $0.1 \%$ solution of trypsin in $0.01 \mathrm{M}$ phosphate buffer of $p \mathrm{H} 7.6$ respectively in the buffer solvent. The slides were removed at various intervals up to a total of 19 hours, i.e., after one, two, three, four, six, 10, 14 , and 19 hours, and examined immediately after staining by the periodic-acid-Schiff technique. As was previously described by Fisher and Creed (1955), the "thrombotic" lesions in the arterioles and capillaries retained their positivity to the periodic-acid-Schiff reaction. It was our aim to evaluate the lesions in the medium-sized arteries; the eosinophilic material attached to the fibrous intimal cushion of the artery illustrated in Fig. 4 was completely stained by the periodic-acid-Schiff reaction before beginning the experiment as well as in all control sections. No changes were observed in the first three sections removed from the trypsin solution. In the section removed after the fourth hour of digestion some material was dissolved out of the "thrombotic" mass. Fig. 7 illustrates within the lesion a small, roundish, sharply demarcated area, which became negative to the periodic-acid-Schiff reaction. All the succeeding sections, i.e., up to the nineteenth hour of digestion, disclosed exactly the same picture; only this distinct area lost its stain uptake by the periodic-acid-Schiff reaction.

It is well known that agglutinated platelets, fibrin, and fibrinoid cannot be differentiated conclusively by their tinctorial behaviour. In our case, and in that reported by Meacham et al. (1951), the lesions under discussion contained no

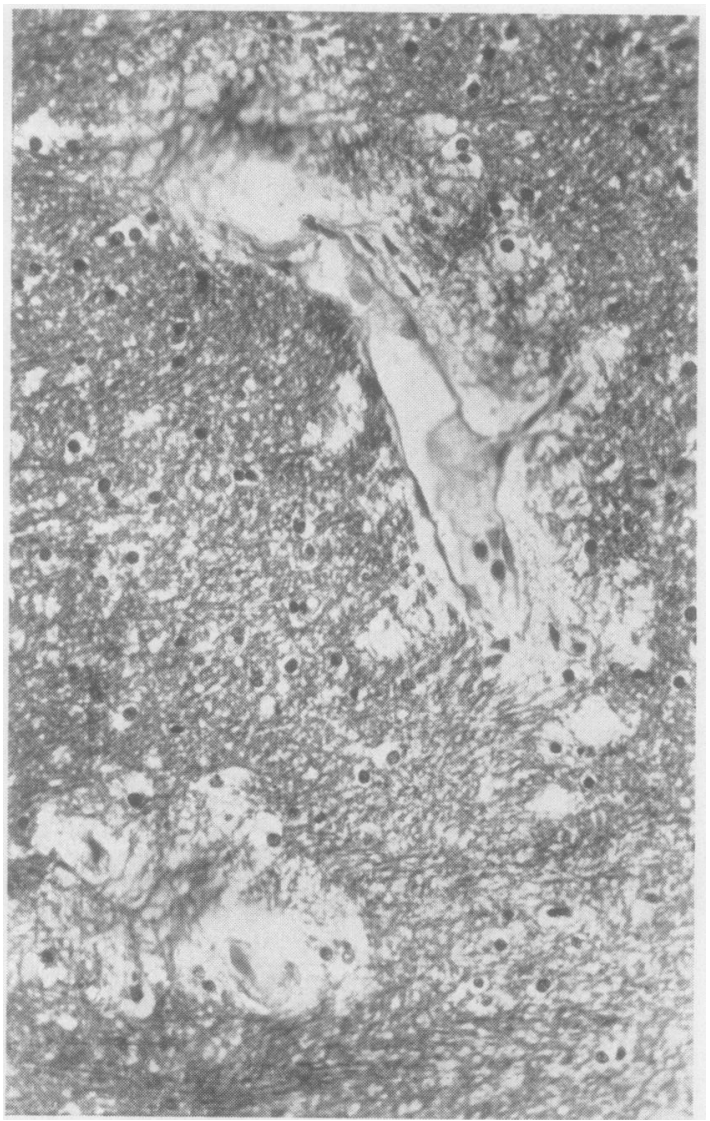

FIG. 6.-Absence of the neuroglia in the vicinity of the blood vessels. Phosphotungstic acid haematoxylin. $\because 80$. 


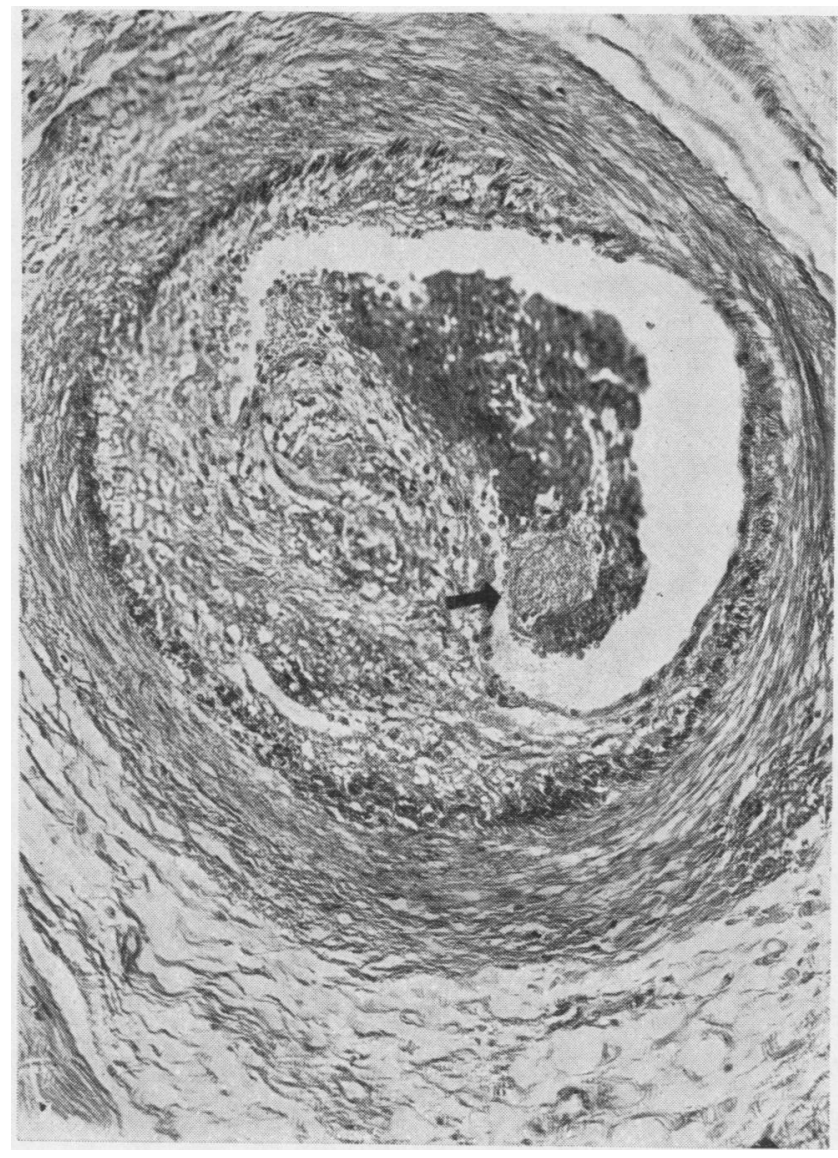

FIG. 7.-Same artery as illustrated in Fig. 4. Periodic-acid-Schiff stain after tryptic digestion. The arrow points out a small area, which became negative after the fourth hour of digestion. $\times 100$.

fibrin demonstrable with the Weigert's and phosphotungstic-acid-haematoxylin stains, but other authors found small amounts of fibrin within the "thrombotic" masses (Symmers and Barrowcliff, 1951 ; Cooper et al., 1952). According to Fisher and Creed (1955), fibrinoid material, contrary to platelets and fibrin, is not digestible by trypsin. It is our opinion that the available evidence allows the conclusion that the "thrombotic" lesions in the small as well as in the medium-sized vessels consist chiefly of a material identical with, or at least closely related to, fibrinoid, but, on the other hand, they contain a small amount of agglutinated platelets and/or fibrin. The failure to demonstrate this relationship in the arterioles and capillaries containing "thrombotic" lesions may be due to a more thorough combination of fibrinoid and platelets and/or fibrin in the small vessels, thus making the recognition of minimal digestible amounts impossible with the magnifications obtainable with the light microscope.

\section{Discussion}

In the brain and heart recent ischaemic infarctions, reparative processes, and scarring were found. It is, therefore, significant to call attention to the fact that only few arterioles and capillaries were occluded by fibroblastic proliferation, whereas the majority of the vessels contained unaltered "thrombotic" lesions. Hence it follows that the vascular lesions of thrombotic thrombocytopenic purpura, in spite of long duration, which was at least 18 months in our case, are distinguished by a limited tendency to organization. It may be assumed that the pathological changes described in the cerebral vessels preceded the clinical manifestations by a certain period of time, insofar as in relatively large brain areas only the successive alteration of a vast number of arterioles and capillaries could cause the foci of malacia. It was Gore (1950) who established the fact that the pathological process is "episodic and occurs in crops." With the progression of the cerebral lesions, signs of participation of both hemispheres became evident. It is noteworthy that, in spite of the involvement of many organs, the illness of our patient was characterized, except terminally, only by a neurological disorder.

Our observations are in accord with the opinion of other authors (Fisher and Creed, 1955 ; March, 1954) that the "thrombotic" lesions conform to the reactions of fibrinoid, but, in consistency with our investigations, we believe that fibrin and/or platelets take part in their formation. It was recently proved that fibrinoid is composed principally of fibrin (Gitlin, Craig, and Janeway, 1957), and Craig and Gitlin (1957), using fluorescein-labelled antisera, showed that the "thrombotic" material in thrombotic thrombocytopenic purpura is composed of fibrin or an insoluble derivative of fibrinogen.

In the literature available to us we did not encounter the description of diffusion of periodicacid-Schiff-positive material into the nervous tissue. With regard to the divergence of views in the literature (Jakob, 1927) concerning structures of such a kind, it is our opinion that the observation does not reflect an artifact, but rather that the same material, which was present as plugs in the lumina of the blood vessels and as a 
subendothelial accumulation, penetrated into the nervous tissue through the damaged vessel walls and diffused into the surrounding tissue.

\section{REFERENCES}

Adams, R. D., Cammermeyer, J., and Fitzgerald, P. J. (1948). J. Neurol. Psychiat., 11, 27.

Allen, A. C., and Sirota, J. H. (1944). Amer. J. Path., 20, 1025.

Beigelman, P. M.(1951). A.M.A. Arch. Path., 51, 213.

Burke, H. A., and Hartmann, R. C. (1959). A.M.A. Arch.intern. Med.. 103, 105 .

Cooper, T., Stickney, J. M., Pease, G. L., and Bennett, W. A. (1952). Amer. J. Med., 13, 374.

Craig, J. M., and Gitlin, D. (1957). Amer. J. Path., 33, 251

Engel, G. L., Scheinker, I. M., and Humphrey, D. C. (1947). Ann. intern. Med., 26, 919.

Fisher, E. R., and Creed, D. L. (1955). Amer. J. clin. Path., 25, 620.
Frick, P. G., and Hitzig, W. H. (1959). Schweiz. med. Wschr. 89, 58. Gitlin, D., Craig, J. M., and Janeway, C. A. (1957). Amer. J. Path., 33, 55

Gore, I. (1950). Ibid., 26, 155 .

Hauser, A., Beyer, A., and Burger, R. A. (1951). A.M.A. Arch Neuro!' Psychiat., 65, 672.

Hellstrom, H. R., Nash, E. C., and Fisher, E. R. (1959). Gastroenterology, 36, 132.

Jakob, A. (1927). Normale und pathologische Anatomie und Histologie des Grosshirns, p. 300. Deuticke, Leipzig and Vienna.

Ladwig, H. A. (1953). Neurology, 3, 267.

March, H. W. (1954). Circulation, 10, 43

Meacham, G. C., Orbison, J. L., Heinle, R. W., Steele, H. J., and Schaefer, J. A. (1951), Blood, 6, 706.

O'Brien, J. L., and Sibley, W. A. (1958). Neurology, 8, 55.

Orbison, J. L. (1952). Amer. J. Path., 28, 129.

Sharnoff, J. G., and Kim, E. S. (1958). A.M.A. Arch. Path., 66. 176.

Stuart, A. E., and MacGregor-Robertson, G. (1956). Lancet, 1, 475.

Symmers, W. St. C. (1956). Brain, 79, 511.

Wyat and Barrowcliff, D. F. (1951), J. Path. Bact. 63, 552

Wyatt, J. P., and Lee, R. S. (1950). A.M.A. Arch. Path., 49, 582. 